\title{
LIÇÕES DA PANDEMIA: QUESTÕES PARA REORGANIZAÇÃO DA SOCIEDADE
}

\author{
G. T. C. DE SOUZA \\ Universidade Federal do Rio Grande do Norte \\ gustavotanus@ufrn.edu.br ${ }^{1}$
}

Submetido 31/07/2020 - Aceito 11/12/2020

DOI: $10.15628 /$ holos.2020.10867

\section{RESUMO}

Apresentamos a resenha da obra: SANTOS, Boaventura

de Sousa. A Cruel Pedagogia do Vírus. São Paulo:

Boitempo, 2020. (Pandemia Capital).

PALAVRAS-CHAVE: Boaventura de Sousa Santos, Pandemia, Coronavírus, Crise, Sociologia.

\section{PANDEMIC LESSONS: ISSUES FOR REORGANIZING SOCIETY}

\begin{abstract}
We present the work's review: SANTOS, Boaventura de Sousa. A Cruel Pedagogia do Vírus. São Paulo: Boitempo, 2020. (Pandemia Capital).
\end{abstract}

KEYWORDS: Boaventura de Sousa Santos, Pandemia, Coronavirus, Crisis, Sociology. 


\section{APRESENTAÇÃO}

O livro A cruel pedagogia do vírus, de Boaventura de Sousa Santos ${ }^{1}$, faz parte de uma coleção da Editora Boitempo. Esta, intitulada "Pandemia capital", é composta por ensaios de intelectuais ${ }^{2}$ sobre a crise da COVID-19, publicados em pequenos e-books, com um projeto gráfico das capas desenvolvido pelos artistas Flávia Bomfim e Maguma (conferir Figura 1). Os textos dessa coleção, ao que inclui este que é objeto desta resenha, são uma resposta em tempo para as questões que foram amplificadas, modificadas pela atual crise que possui implicações, não apenas na economia, como muitos têm imaginado, mas nas relações humanas, na psicologia, na educação, implicações políticas que reorientarão um novo campo de ação.

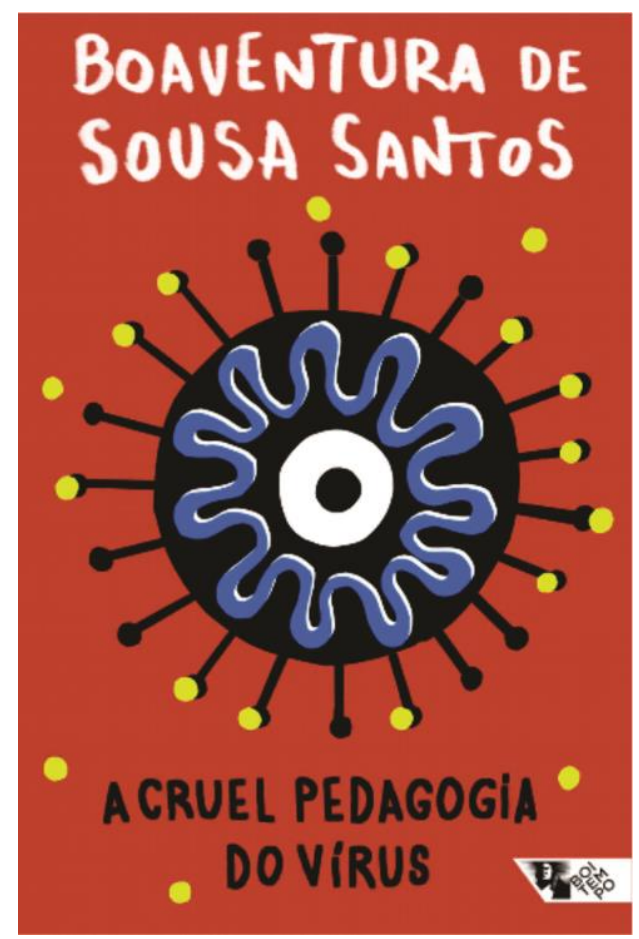

Figura 1: Capa do livro.

O livro de Boaventura, que foi editado no Brasil quase simultaneamente à edição portuguesa da Almedina, em abril de 2020, corresponde a uma reflexão sobre questões atuais, em um ensaio não apenas sobre crise da pandemia, mas ao que esta crise tem revelado sobre o modo

\footnotetext{
${ }^{1}$ Boaventura de Sousa Santos é professor catedrático aposentado pela Faculdade de Economia da Universidade de Coimbra e Distinguished Legal Scholar da Universidade de Wisconsin-Madison, nos Estados Unidos. É também diretor emérito do Centro de Estudos Sociais da Universidade de Coimbra e coordenador científico do Observatório Permanente da Justiça Portuguesa. Autor reconhecido e premiado, tendo textos traduzidos para o espanhol, inglês, italiano, francês, alemão, chinês, tem escrito amplamente para as áreas de sociologia do direito, sociologia política, epistemologia e estudos pós-coloniais, sobre movimentos sociais, globalização, democracia participativa, reforma do Estado e direitos humanos, além de fazer trabalho de campo em Portugal, no Brasil, na Colômbia, em Moçambique, em Angola, em Cabo Verde, na Bolívia e no Equador.

${ }^{2}$ Os outros títulos são: Crise e Pandemia, de Alysson Leandro Mascaro; $A$ arte da quarentena para principiantes, de Christian Dunker; Reflexões sobre a peste, de Giorgio Agamben; Construindo movimentos: uma conversa em tempos de pandemia, de Angela Davis e Naomi Klein; Coronavírus: o trabalho sob fogo cruzado, de Ricardo Antunes; (Re)nascer em tempos de pandemia: uma carta à Moana Mayalú, de Talíria Petrone; Pandemia: Covid-19 e a reinvenção do comunismo, de Slavoj Zizek.
} 
de gestão política, econômica e social, despreocupado com os destinos da população humana (pela precarização da vida), da natureza (pela destruição dos recursos que mantém/manterão a vida).

\section{CORPO DA ANÁLISE}

Formalmente, o ensaio foi dividido em cinco capítulos. No primeiro, intitulado "Vírus: tudo o que é sólido se desmancha no ar". Nele, o autor realiza uma divisão conceitual de questões relacionadas à excepcionalidades (das crises), à elasticidade (dos modos de vida), à fragilidade (do humano), vulneráveis, frente à sanha de lucro: pelo esgotamento dos recursos naturais, pela destruição do ambiente em que vive, pelas invisibilidades, existentes, e as que virão a existir.

Nesse capítulo, o autor elabora uma questão que será respondida, ao menos sugeridas outras questões relacionadas, para as quais a sociedade deverá ter posicionamentos, se quiser sobreviver as crises, tanto essa, quanto as vindouras: Que potenciais conhecimentos decorrem da pandemia do coronavírus? Um princípio de reflexão está em perceber que as crises não são excepcionais, mas parte da expansão/avanço de uma ideologia que sujeita os cidadãos, os estados, à lógica do setor financeiro. Assim, é de interesse investigar as temporalidades das crises, pois se elas se confirmam passageiras, estuda-se os fatores que as provocam, preparando-se para as vindouras. Entretanto, quando a crise é única, e distendida, permanente, ela passa, então, a ser justificativa para a desagregação/destruição de direitos sociais importantes. Essa é a tese geral do livro: as crises e os modos de gestão delas. Em pergunta delineada, o sociólogo nos impele a inquirir sobre o porquê de a crise ser permanente. Ela, assim, justificaria a concentração de riqueza e boicota "medidas eficazes para impedir a iminente catástrofe ecológica". (p. 5). Apenas com a irrupção de uma pandemia, tal qual estamos vivenciando, que se torna possível experimentar outras formas de vida, de subjetividade, alternativas que desmoronam a vida dentro de modelo imposta. Isto é, as alternativas delineadas pelas crises - pandêmicas, desastres ambientais, colapsos financeiros - deverão ser forçosamente a alternativa, justamente porque o sistema político havia deixado de discuti-las.

Nesse momento, uma ideia de comunhão planetária passou a pairar, mesmo que as pandemias tenham alvos certos, tal como o autor tratará no capítulo 3. Isso porque para uma classe privilegiada, a sensação de segurança, dada por recursos tais como cuidados médicos, apólices de seguro, serviços de empresas de segurança, terapia psicológica, academias de ginástica" (p. 6) não são suficientes frente a um novo inimigo invisível. Estranha comunhão essa em que a solidariedade é estar justamente isolado dos outros. Com isso, houve um arrefecimento das atividades econômicas, o que gerou consequências negativas, dadas como certas, porém, também positivas, tais como a diminuição da poluição atmosférica. Isso têm revelado outros horizontes, além da necessidade de pensarmos em desenvolvimento com conservação ecológica. Apesar de a pandemia mundial ser acompanhada de uma comoção mundial, é necessário observar as sombras que acompanham a visibilidade: vulnerabilidade de populações refugiadas, ou em campos de imigrantes detidos, onde não há condições para sobrevivência. Há zonas de invisibilidade existentes e as que virão a existir, por conta das crises.

Já no segundo capítulo, "A trágica transparência do vírus", o autor trata das relações e reações frente às forças invisíveis, transparências, por mostrar-se, e por não deixar ser visto. 
Segundo Boaventura, os debates culturais, políticos e ideológicos desse nosso tempo não têm sido francos porque afastados do cotidiano vivido pela grande maioria. A política não tem atuado como mediadora entre as ideologias e as necessidades dos cidadãos e, se há alguma mediação é com os mercados. O facho de luz que esse mercado nos apontava, empalideceu com a pandemia, permitindo surgir uma outra claridade: o que tal claridade permite ver e o modo como interpretamos o visto marcará o futuro da civilização. Na subseção "A pandemia é uma alegoria": o sentido literal da pandemia é o medo caótico generalizado e a morte sem fronteiras, causados pelo inimigo invisível. Mas sua expressão vai além, porque abarca o invisível: o vírus cuja morada se dá nos corpos, deus, nos templos, os mercados, nas bolsas de valores. Assim, estariam representados três reinos.

No 10 reino, o mais invisível e imprevisível é o reino de: deus, vírus e mercado. Nele, se salvarão os mais fortes (mais santos, mais jovens, mais ricos). No 2 reino, o reino das causas, das mediações entre o humano e o não humano, é composto do que chama de três unicórnios: o capitalismo, o colonialismo e o patriarcado. Como modos de dominação, são "destemperados, ferozes e incapazes de se dominar". Sua ferocidade não é apenas da bruteza da força, mas da astúcia, mesmo que possuam um ponto fraco, que é sucumbir à astúcia de quem o souber identificar" (p. 11). Invisíveis em sua essência, pois que os humanos são educados e doutrinados permanentemente para não os ver. Afirma o capitalismo que todos são iguais; mas, como existem diferenças entre eles, haverá, afirmam o colonialismo e o patriarcado, diferenças na igualdade entre considerados inferiores e os autoproclamados superiores. Tais unicórnios são astutos, de dois modos. No primeiro modo, eles desaparecem sem morrer, parecem fracos sendo fortes: o capitalismo, com controle de fora, em plena Revolução Russa; tendo hoje vitalidade dentro do maior inimigo, a China, (que logo será a primeira economia); o Colonialismo, aparentemente desaparecido com as independências dos países colonizados, metamorfoseado o controle pelas novas formas, como o "neocolonialismo, imperialismo, dependência, racismo etc." (p. 12); e o Patriarcado, aparentemente moribundo, por conta dos sucessos dos movimentos feministas, vivente nas violências domésticas, discriminação sexista e no número em ascensão de feminicídios. O segundo modo de astúcia é mascarar sua interconexão, sendo que juntos é que eles têm poder para dominar. No 3o reino, o das consequências, é onde os unicórnios mostram sua face real. Nele, a maioria da população consegue vislumbrar, mesmo que com dificuldade, duas paisagens principais: concentração de riqueza/extrema desigualdade social; destruição da vida do planeta/iminente catástrofe ecológica; estas que levarão a humanidade à morte.

No capítulo 3, "A sul da quarentena", o autor trata dos grupos sociais que têm dificuldades para estar em quarentena porque possuem uma vulnerabilidade especial que precede essa quarentena e se agrava com ela. Boaventura nomeia-os de Sul; não como espaço geográfico, mas como um espaço-tempo político, social e cultural. "Metáfora do sofrimento humano injusto causado pela exploração capitalista, pela discriminação racial e pela discriminação sexual" (p. 15). São eles:

- "As mulheres", cuja quarentena é perigosa, tanto porque prestam cuidados dentro de fora das famílias; exercem profissões ligadas à saúde, linha de frente da prestação de cuidados aos doentes e idosos, quanto porque, em confinamento, experenciando um 
dos momentos em que a violência (que já existe) contra elas torna-se maior: que é a crise.

- "Os trabalhadores precários, informais, ditos autônomos" (p. 16): atualmente o grupo de trabalhadores mais abundante, por conta das políticas neoliberais, eles são os mais rapidamente despedidos quando há crises econômicas, assim, o que será deles? 0 trabalho em casa, possível para as classes médias, para eles, significa passar fome. Escolha: morrer de vírus ou de fome.

- "Os trabalhadores da rua" (p. 17): grupo específico de trabalhadores precários, são os vendedores ambulantes. Dependem da rua, isto é, de quem transita e por acaso para e compra algo. Eles, há muito, vivem em quarentena, na rua, na rua com gente. Boaventura fala também dos uberizados da economia informal, que são os entregadores de comida e encomendas em domicílio. Eles são os que garante a quarentena de muitos; isto significa que o negócio aumenta tanto quanto o risco que eles correm.

- "Os sem-abrigo ou populações de rua" (p. 18): Como estar em casa, em quarentena, se não se tem casa? Não estariam eles, já, em quarentena antes da pandemia?

- "Os moradores nas periferias pobres das cidades, favelas, barriadas, slums, caniço, etc." (p. 20): "Segundo a ONU, 1,6 bilhão de pessoas não têm habitação adequada, [...]" isto é, vivem em bairros informais, sem infraestruturas, saneamento básico, acesso aos serviços públicos, água, eletricidade. O que é o autoisolamento para quem já vive isolado das políticas públicas? Nesses espaços os cidadãos morrem por falta de acesso aos direitos de cidadão (saúde, educação, alimentação, trabalho, sanamento básico etc.).

- "Os internados em campos de internamento para refugiados, os imigrantes indocumentados ou as populações deslocadas internamente" (p. 20), são formados por populações confinadas, em permanente quarentena, e por populações deslocadas vivem em locais muito distantes dos centros de saúde. Têm morrido por enfermidades para as quais existem tratamento, como malária, diarreia.

- "As pessoas com deficiência" (p. 20): têm sido vítimas de formas de dominação, dentro do que se chama "capacitismo". Este é baseado numa sociedade em que as pessoas com deficiência seriam exceções anormalidades que deveriam ser aniquiladas, superadas. Com isso, não são reconhecidos seus direitos, o que faz com que "se sintam em quarentena permanente". (p. 20).

- "Os idosos": grupo numeroso no "Norte global" é vulnerável, porém sem indiscriminação. Quem é idoso?, o autor interroga. Há localidades em que a diferença na expectativa de vida em bairros pobre e rico é de vinte anos. Idosos, nesse norte global são "depositados" em asilos que podem ser desde "cofres de luxo a depósitos de lixo humano". (p. 21). Os que vivem nesses asilos já vivenciam a quarentena. Entretanto, o que fazer, caso esses lugares se contaminem? No "Sul global", epidemias anteriores fizeram com que os idosos prolongassem a vida ativa, por conta da morte dos pais jovens, fazendo com que os avós tenham que assumir o lugar.

Haverá bem mais grupos que podem ser colocados na "lista dos que estão a sul da quarentena", como, por exemplo as pessoas em situação de encarceramento, as pessoas com depressão etc. Diferente de como é lida a questão (pela mídia e organizações) a quarentena não apenas torna mais visíveis como também reforça a "injustiça, a exclusão social e o sofrimento 
injusto" (p. 22). Sendo que justamente neste momento as assimetrias estão mais invisíveis por conto do pânico daqueles que nunca sofreram privação de direitos.

No capítulo 4, "A intensa pedagogia do vírus: as primeiras lições", o autor apresenta possíveis lições a serem aprendidas. A primeira lição "O tempo político e mediático condiciona o modo como a sociedade contemporânea se apercebe dos riscos que corre" (p. 23) diz que as graves crises, as agudas, rápidas, mobilizam forças política e midiática - que conduzem medidas que resolvem as consequências delas, jamais as causas. As crises graves, porém, de progressão lenta, têm passado despercebidas, sendo que os efeitos são/serão maiores. O primeiro caso, a pandemia do coronavírus; no segundo, a poluição atmosférica. Esta crise, climática, não mobiliza por uma resposta dramática e urgente, o que a torna irreversível.

A segunda lição, "As pandemias não matam tão indiscriminadamente quanto se julga": se o vírus não discrimina na hora de destruir os pulmões de quem está contaminado, tanto o modelo político quanto as políticas públicas, sim, colocam-no mais próximo das populações vulneráveis das quais tratou no capítulo anterior. A terceira lição, "Enquanto modelo social, o capitalismo não tem futuro", o autor mostra-nos que a versão vigente do capitalismo, esse neoliberalismo em que o capital financeiro é que dita regras (de vida, de morte), tem sido desacreditada social e politicamente. Ele, que, desde a queda do muro de Berlim, vem impondo uma versão "antissocial" do capitalismo: o modelo de negócio do capital em que a gestão deve permitir o maior lucro para os investidores. Tal modelo destrói a lógica do serviço público, inclusive com a propagação de uma ideologia que o demoniza, ao passo que montam as chamadas "políticas de austeridade", que, à título de uma crise financeira, ignoram as políticas sociais, privatizam os serviços públicos. Com isso, ignoram os princípios de cidadania e de direitos humanos. É possível perceber a fratura entre a dita economia da saúde e a saúde pública: os governos menos neoliberais são os que melhor estão lidando com a pandemia. Neste momento, as instituições financeiras fomentam os empréstimos, para "arcar com os gastos" emergenciais, o que endivida mais ainda os Estados, fazendo com que o futuro pós-crise da pandemia seja um futuro com mais políticas de austeridade, de degradação aos serviços públicos. Isso coloca para os cidadãos uma questão: haverá, possivelmente, outras pandemias, e as políticas neoliberais, que continuarão a destruir a capacidade dos Estado para responder a essas crises, o que deixará as populações ainda mais indefesas. Tal ciclo pode ser interrompido, interrompendo-se seu causador.

A lição quarta, "A extrema-direita e a direita hiper-neoliberal ficam definitivamente (espera-se) descreditadas", grupo que tem crescido pelo mundo, formado por pessoas que possuem uma pulsão antissistema, manipulam instrumentos democráticos, ao que se inclui o judicial, caracterizam-se por um nacionalismo excludente, xenófobo, racista; são apologistas do "Estado de exceção securitário", atacam as investigações científicas independentes, a liberdade de expressão, estigmatizam os adversários, que são vistos/tratados como inimigos a serem aniquilados. Mantém discurso de ódio, inclusive nas redes sociais, locais de comunicação dessa política de ideologia excludente. Defendem o Estado mínimo, porém, com máximo investimento nas máquinas de guerra e de controle. Elas, segundo o autor, têm ocupado lugares de governos de esquerda que fracassaram; porém, não só, pois ocupam lugares de governos que investiram em sua autonomia, nas populações mais pobres. Em alguns países, esses extremistas são também conservadores religiosos, reacionários. Estados que são comandados por tais governos de extrema 
direita ou de direita neoliberal falharam na ação contra a pandemia: ocultaram informações, desprestigiaram a comunidade científica, minimizaram efeitos negativos, utilizando a crise para realização de chicana política (p. 27); fomentaram a ideia de que um "darwinismo social" seria benéfico, pois eliminar-se-iam grupos que consideram desinteressantes, descartáveis. A título de salvar a economia, colocaram as populações em risco, pelo o que o autor acredita que serão responsabilizados.

A quinta lição, "O colonialismo e o patriarcado estão vivos e reforçam-se nos momentos de crise aguda": As crises só se tornam questão global quando atacam países mais ricos: epidemias vêm matando populações mais pobres, sem que seja noticiado, sem que haja comoção. Concomitante a isso, "corpos racializados e sexualizados são sempre os mais vulneráveis perante um surto pandêmico", seja pela discriminação a que estão sujeitos, seja porque estão mais expostos à propagação do vírus, seja porque os cuidados não chegam aos locais onde vivem. Isso, também, porque as políticas de prevenção ou contenção de alguma crise são seletivas, isto é, não são universais. Muitas vezes tais políticas são adeptas do darwinismo social, garantindo a sobrevivência dos corpos socialmente mais valorizados, como sendo os mais aptos e necessários para a economia.

A sexta e última lição, "O regresso do Estado e da comunidade" (p. 28): a regulação das sociedades modernas se dá pelos princípios do Estado, do mercado, da comunidade. Nos últimos anos, prioriza-se o mercado em detrimento dos outros. Quer seja pela privatização dos bens sociais coletivos, quer seja pela gestão e avaliação desses entes (e suas atividades) por uma lógica do mercado, por critérios de rentabilidade. Assim, os serviços públicos são avaliados, para justificar sua precarização; a educação ranquiada, produtivista, e que estudantes são consumidores de serviço. Assim, surgiram as parcerias público-privadas, que são "mecanismo de transferência de recursos públicos [do Estado] para o setor privado" (p. 29).

As pandemias mostram como o capitalismo neoliberal desestruturou o Estado para responder às emergências, e continuarão dando importantes lições.

No quinto e último capítulo, intitulado "O futuro pode começar hoje" (p. 30), o autor conclui que a pandemia e a quarentena estão mostrando que conseguimos nos adaptar a novos modos de viver, quando é necessário e sentido como um bem comum; e isso são alternativas possíveis, senão necessárias, buscando novas maneiras de viver, produzir, consumir, conviver, para evitar novas pandemias, que deverão ser, se seguirmos essa política para o mercado, mais letais. Mas como tornar isso uma ação política concreta?

É provável, levanta o autor, que as pessoas, passado o momento crítico da quarentena, saiam às ruas, como que para assegurar "que o mundo que conheceram afinal não desapareceu" (p. 30). Isso terá efeito amenizador das rotinas monótonas e pesadas anteriores, que poderão parecer mais leves e sedutoras. O retorno à normalidade não deverá ser fácil, pois terão trabalho, salário? Como recuperar os atrasos na educação e nas carreiras? O Estado de exceção, gestado para responder à crise, desaparecerá? As medidas de proteção à vida deixarão de ser prioritárias? "Haverá vontade de pensar em alternativas quando a alternativa que se busca é a normalidade que se tinha antes da quarentena?" (p. 31). Conectarão tal normalidade à crise que ela causou ou contribuiu para o agravamento? 
Antes da pandemia já aconteciam protestos contra as desigualdades, a corrupção e falta de proteção social, e provavelmente continuarão, passado o período da pandemia; o que será respondido com violência repressiva pelos governos, que exigirão que os cidadãos baixem expectativas e passem a habituar-se ao "novo normal" (p. 31).

As pandemias vindouras deixarão de ser questão política, já que os políticos que atuarão nela serão os que já passaram por essa. Para o autor, só não será desse jeito se a sociedade se organizar ("partidos políticos, movimentos e organizações sociais espontâneas de cidadãos e cidadãs") com o fito de resolver a separação entre "processos políticos e os civilizatórios" (p. 32), esta que se vem ocorrendo desde a queda do muro e do desenvolvimento da ideia de que não há alternativa ao capitalismo e a seus efeitos.

Desde o início do século $\mathrm{XX}$, as discussões sobre alternativas ao modelo se davam no ambiente político, no processo de debate iam adquirindo dimensão civilizatória. Entraram na agenda de debates modelos de desenvolvimento que pensavam em atenuar a agressão à natureza, por exemplo. Tais debates não se assemelhavam ao modelo que existia do lado soviético, mas a existência legitimava o muro. Após a queda do muro, a articulação se desfez, e os debates assumiram apenas modos de gerir "soluções propostas ou impostas pela (des)ordem capitalista vigente" (p. 32). Tal separação, entre modelos de gestão da economia e modelos alternativos econômico, social, político, cultural - de desenvolvimento da vida e da sociedade, permitiu deixar, em separado, alternativas de vida que tornassem a vida possível (destruição da natureza, dos recursos, etc.).

Apenas com uma nova articulação entre processos políticos e civilizatórios que conseguiremos pensar em uma sociedade que respeite a vida, incluída a humana. Nova articulação: "viragem epistemológica, cultural e ideológica que sustente as soluções políticas, econômicas e sociais que garantam a vida humana digna no planeta" (p. 33). Quarentena dentro da quarentena, preexisente, forjada pelo capitalismo. Esta é política, cultural e ideológica. “[...] imaginar o planeta como uma casa compartilhada, e a natureza como nossa mãe originária, a quem devemos amor e respeito." (p. 33).

\section{CONSIDERAÇÕES}

Assim, o livro aponta, didaticamente, para o que devemos colocar como centro de uma luta para conservação: a vida de todas as pessoas. E para qual seja a resposta, implicará em uma outra relação com a natureza.

\section{REFERÊNCIAS}

Santos, B. S. (2020). A Cruel Pedagogia do Vírus. São Paulo: Boitempo. (Pandemia Capital).

\section{COMO CITAR ESTE ARTIGO:}

Souza, G. T. C. de. (2020). Lições da pandemia: questões para reorganização da sociedade. Holos. 36(5), 19. 


\section{SOBRE OS AUTORES}

\section{G. T. C. DE SOUZA}

Doutorando em Estudos da Linguagem/ Literatura Comparada, pela Universidade Federal do Rio Grande do Norte, com intercâmbio na Faculdade de Educação da Universidade Federal de Minas Gerais. É mestre em Teoria da Literatura e Literatura Comparada, pela UFMG. Bacharel e licenciado em Estudos Literários/Língua Portuguesa, e Bacharel em Edição, por esta mesma instituição, onde é pesquisador do Núcleo de Estudos Interdisciplinares da Alteridade (FALE/UFMG), e integrante da comissão editorial do portal literafro - O portal de literatura afro-brasileira. É, também, pesquisador do Moviola - grupo de estudos de literatura, cinema e outras artes. É autor dos livros "Africanos e afrodescendentes nas estantes: a Biblioteca Pública Estadual de Minas Gerais" (Faculdade de Letras/UFMG, 2017) e "A Hagbe que nos guarde..." (Editora IFRN, 2019).

E-mail: gustavotcs@gmail.com

ORCID ID: http://orcid.org/0000-0002-5696-7187

Editor(a) Responsável: Francinaide de Lima Silva Nascimento

Pareceristas Ad Hoc: Francinaide de Lima Silva Nascimento

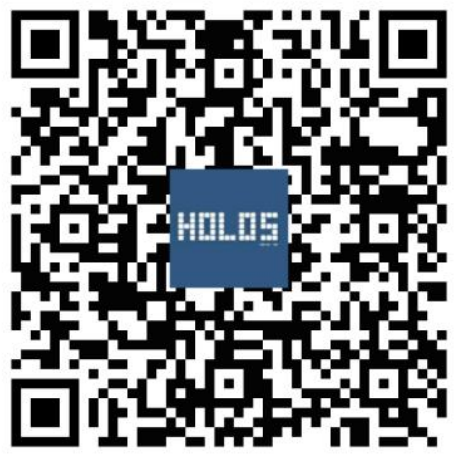

